ЛИВАНОВА Ирина Владимировна - кандидат политических наук, доцент Сибирского института международных отношений и регионоведения (630075, Россия, г. Новосибирск, ул. Народная, 14; iv-livanova17@mail.ru)

САЛАМОВ Руслан Рустемович - аспирант Сибирского института международных отношений и регионоведения (630075, Россия, г. Новосибирск, ул. Народная, 14; ruslan5215@таil.ru)

\title{
ПАРАДИПЛОМАТИЯ РЕГИОНОВ БРАЗИЛИИ: ПОЛНОМОЧИЯ И ПРЕДМЕТЫ ВЕДЕНИЯ
}

Аннотация. Статья посвящена изучению ключевых аспектов парадипломатии бразильских регионов. В работе рассмотрена проблема разграничения полномочий и предметов ведения между федеральным центром и субъектами Федеративной Республики Бразилия, проанализирован опыт осуществления парадипломатии четырех ведущих бразильских штатов: Рио-де-Жанейро, Минас-Жерайс, Сан-Паулу и Риу-Гранди-ду-Сул.

Ключевые слова: парадипломатия, полномочия, предметы ведения, союз, федеральный округ, штаты

$\mathrm{C}$ овременный этап развития международных отношений характеризуется активизацией двустороннего и многостороннего сотрудничества государств. Особую роль в этом процессе начинают играть международные связи регионов государств. Для более полного и точного отражения этих тенденций в политической науке стал использоваться термин «парадипломатия», который трактуется как отношения между субрегионами государств в развитом обществе, фокусирующиеся на региональном уровне между правительствами двух государств [Яковлева, Левкин 2014: 18]. Существует ряд подходов к определению данного термина. Парадипломатию, в целом, определяют как участие субнациональных единиц в международных отношениях через установление формальных и неформальных, постоянных и временных связей с иностранными акторами с целью достижения определенного набора задач через различные стратегии действия на международной арене [Кузнецов 2006: 76]. В данном случае акцент делается на субнациональном характере парадипломатических акторов, которые находятся внутри государств и по отношению к ним являются единицами более низкого, а главное - подчиненного порядка. Однако может подчеркиваться и другой аспект [Акимов 2016: 26]. В частности, С. Уолф полагает, что парадипломатия - это внешнеполитические возможности субгосударственных субъектов, их независимое от государства участие в деятельности на международной арене по достижению их собственных особых международных интересов [Wolff 2007: 141-142]. В этом случае ключевое определение - «независимое»; оно подчеркивает обособленность внешних связей субгосударственных акторов от политики того государства, к которому они принадлежат [Акимов 2016: 26]. Исходя из вышеизложенного, в данном научном исследовании под термином «парадипломатия» мы понимаем систему внешних связей регионов государств.

В этом контексте особый интерес для Российской Федерации представляет анализ опыта бразильских регионов в сфере парадипломатии, что обусловлено наличием основополагающих факторов. Во-первых, проблема изучения парадипломатии регионов Бразилии в настоящее время актуальна не только для РФ, но и для других федеративных государств мира в связи с возможностью использования положительного опыта многолетнего международного сотрудничества регионов Бразилии с зарубежными партнерами для совершенствования и развития парадипломатии регионов современных федеративных госу- 
дарств. Во-вторых, актуальность изучения данной проблемы для РФ определяется целым рядом ключевых аспектов, наличие которых обусловлено схожей формой государственного устройства обеих стран: прежде всего, и Россия, и Бразилия имеют федеративную форму государственного устройства; в основу формирования Российской Федерации положены административно-территориальный и национально-территориальный принципы образования субъектов, а субъекты Федеративной Республики Бразилия образованы по административно-территориальному принципу; оба государства можно условно отнести к асимметричному типу федераций; субъекты РФ и Бразилии активно участвуют в процессе осуществления международных связей регионов, устанавливая и развивая межрегиональные связи с аналогичными субнациональными единицами других государств. С учетом этого не вызывает сомнения тот факт, что исследование опыта бразильских регионов в сфере парадипломатии будет интересно и полезно для развития регионов РФ.

Особенности международных связей регионов государств, а также проблемы разграничения полномочий между центром и субъектами федеративных государств исследованы в научных трудах О.В. Дубровиной (Плотниковой) и О.Ю. Дубровиной, а также Е.А. Кремянской [Плотникова, Дубровина 2016; Кремянская 2015]. Сущность, понятие и тенденции парадипломатии в контексте региональной идентичности субъектов федераций представлены в работе Ю.Г. Акимова [Акимов 2016]. Среди трудов ученых Института Латинской Америки РАН следует выделить работы, посвященные отношениям государств БРИКС с регионом Латино-Карибской Америки и приоритетам региональной политики Бразилии [БРИКС - Латинская Америка... 2014], а также работы, в которых рассмотрены вопросы инновационного развития государств Латино-Карибской Америки, в т.ч. Бразилии и ведущих бразильских штатов [Возможности и пределы... 2017]. Среди бразильских ученых проблемами сущности, полномочий и предметов ведения парадипломатии штатов Бразилии занимались Ж. Маркович, П. Даллари [Marcovitch, Dallari 2014] и другие исследователи. Однако на сегодняшний момент проблема парадипломатии штатов Бразилии остается малоизученной в современной отечественной и зарубежной научной литературе.

Целью настоящей статьи является изучение полномочий и предметов ведения регионов Бразилии в сфере парадипломатии. Целевая направленность обусловила необходимость изучить проблему разграничения полномочий и предметов ведения между центром и субъектами Федеративной Республики Бразилия; проанализировать организационные механизмы и опыт осуществления парадипломатии ведущих бразильских штатов - Рио-де-Жанейро, Минас-Жерайс, Сан-Паулу и Риу-Гранди-ду-Сул.

Приступая к исследованию, необходимо отметить, что в настоящее время отличительной чертой современных международных отношений является выход на мировую арену большого числа разнообразных несуверенных/негосударственных акторов. К числу таких акторов международных отношений относятся, в частности, регионы федеративных государств, которые активно устанавливают международные связи с зарубежными партнерами в различных областях. В современном мире происходит формирование системы внешних связей регионов государств. Это явление получило собирательное название «парадипломатия» [Акимов 2016: 26].

Разграничение полномочий и предметов ведения федераций и их субъектов в сфере международной деятельности в различных странах осуществляется по-разному [Плотникова, Дубровина 2016: 72]. В связи с этим для проведения политического анализа парадипломатии регионов Бразилии необходимо изу- 
чить и проанализировать основные положения внутригосударственных документов, регламентирующих разграничение компетенций между федеральным центром и субъектами Бразилии.

Современное политико-административное устройство Федеративной Республики Бразилия включает в себя Союз, штаты, Федеральный округ и муниципалитеты, которые пользуются автономией ${ }^{1}$. Следовательно, рассматривая вопрос распределения полномочий и предметов ведения между Бразильским федеральным центром и субъектами, можно условно выделить несколько уровней.

Первый уровень составляет компетенция Союза, к которой относятся такие важнейшие политические функции, как установление и поддержание отношений с иностранными государствами и участие в различных международных организациях; объявление войны и заключение мира; обеспечение национальной обороны. Существует также сфера исключительной компетенции Союза, предполагающая право Союза издавать законы в рамках ведущих отраслей внутригосударственного законодательства ${ }^{2}$.

Второй уровень представлен совместной компетенцией Союза, штатов, Федерального округа и муниципалитетов. Он предполагает сотрудничество между ними в целях охраны демократических институтов и публичного имущества; обеспечения здравоохранения и публичной помощи, защиты и гарантирования прав инвалидов; защиты окружающей среды. Помимо этого, существует конкурирующая компетенция Союза, штатов и Федерального округа. В этом случае Союз, как правило, ограничивается принятием норм общего характера. Это, тем не менее, не исключает дополнительной компетенции штатов. При отсутствии федеральных норм общего характера штаты наделяются полной компетенцией (но это не должно противоречить федеральному уровню) ${ }^{3}$.

К третьему уровню можно условно отнести исключительную компетенцию субъектов федерации (штатов, Федерального округа и муниципалитетов). Данная компетенция носит остаточный характер и включает все оставшиеся предметы ведения, которые не относятся к первому и второму уровню (и, соответственно, не запрещенные на федеральном уровне $)^{4}$. Практика наличия остаточных полномочий показывает, что зачастую практически невозможно предусмотреть все объекты регулирования и управления исключительно на федеральном уровне [Кремянская 2015: 113-114].

Рассмотрим опыт осуществления парадипломатии четырех ведущих штатов Бразилии (Рио-де-Жанейро, Минас-Жерайс, Сан-Паулу и Риу-Гранди-дуСул), осуществляющих международные связи на основе представленных выше уровней разграничения полномочий и предметов ведения Бразилии и ее регионов.

Парадипломатия штата Рио-де-Жанейро. Рио-де-Жанейро имеет один из самых богатых и насыщенных опытов субнационального сотрудничества среди всех остальных штатов Бразилии. Парадипломатия штата Рио-де-Жанейро осушествляется на основе положений федеральных и региональных документов 5 . Для парадипломатии этого штата Бразилии принципиально важны два ключевых аспекта. С одной стороны, это программы, возглавляемые губернатором

\footnotetext{
1 Constituição da República Federativa do Brasil de 1988. URL: http://www.planalto.gov.br/ccivil_03/ Constituicao/Constituicao.htm (проверено 29.06.2018).

2 Ibid.

3 Ibid.

4 Ibid.

5 Constituição do Estado do Rio de Janeiro, de 5 de outubro de 1989. URL: http://alerjln1.alerj.rj.gov.br/ constest.nsf/PageConsEst?OpenPage\# (проверено 29.06.2018).
} 
штата и направленные на перенимание опыта успешной субнациональной политики регионов других стран. С другой стороны, Рио-де-Жанейро стал штабквартирой крупнейших спортивных событий мирового уровня - Чемпионата мира по футболу 2014 и Олимпийских игр 2016, а также провел другие крупные мероприятия, такие как Всемирные военные игры в 2011 г., конференция «Рио + 20» (Конференция Организации Объединенных Наций по устойчивому развитию) в 2012 г., Всемирный день молодежи в 2013 г. (и, помимо этого, ряд важных деловых встреч) [Marcovitch, Dallari 2014: 28-29].

Правительство штата Рио-де-Жанейро осуществляет субнациональное сотрудничество с правительствами регионов ряда государств, в частности стран Западной Европы и Скандинавии, США, Канады, Японии. Сотрудничество осуществляется соответствующими учреждениями и агентствами и принимает формы взаимных визитов и поездок, учебных курсов, семинаров и т.д. До 2002 г. правительство штата Рио-де-Жанейро активно развивало тесное сотрудничество с провинциями Китая и провинциями Кубы. В период с 2003 г. по настоящее время основное внимание уделяется сотрудничеству с провинциями, департаментами, регионами и штатами соседних южноамериканских государств [Marcovitch, Dallari 2014: 33].

Парадипломатия штата Минас-Жерайс. Парадипломатия штата МинасЖерайс также осуществляется в соответствии с положениями федеральных и региональных документов ${ }^{1}$. Разработкой и осуществлением стратегии в области международных связей штата Минас-Жерайс занимается губернатор при поддержке соответствующей институциональной структуры [Marcovitch, Dallari 2014: 41-42].

Штат Минас-Жерайс осуществляет международные связи по следующим основным направлениям: 1) сотрудничество в области обмена студентами в сфере научно-технической подготовки (Яманаси, Япония); 2) инвестиционное сотрудничество в области автомобилестроения, пищевой и металлообрабатывающей сфер производства, информационных технологий (Пьемонт, Италия); 3) сотрудничество в научно-технической, культурной и спортивной сферах (Цзянсу, Китай); 4) интенсивные обмены и дискуссии по вопросам здравоохранения, а также в социальной и культурной областях (Квебек, Канада); 5) добыча полезных ископаемых и окружающая среда (Квинсленд, Австралия); 6) сотрудничество в области информационных технологий, разработки многосекторальных проектов и программ обучения (Сингапур); 7) содействие обмену в рамках межрегионального развития и совершенствования (Нор-Па-де-Кале, Франция); 8) взаимодействие в секторе здравоохранения, в области экономического развития малых и средних предприятий, в сфере спорта и молодежной политики, в сфере инноваций (Ломбардия, Италия) [Marcovitch, Dallari 2014: 44].

C 2013 г. штат Минас-Жерайс успешно реализует программу «Стартапы и развитие предпринимательства в области экосистем», которая привлекла более 80 стартапов, из которых треть являются международными (США, Индия, Испания, Польша) [Возможности и пределы... 2017: 88].

Парадипломатия штата Сан-Паулу. Как и другие штаты Бразилии, СанПаулу осуществляет международные связи с регионами других стран в целях развития взаимной дружбы и уважения. Поскольку в Сан-Паулу размещается крупнейшая диаспора японцев за пределами Японии, правительство штата уделяет особое внимание развитию международных связей с японскими префек-

\footnotetext{
1 Constituição do Estado de Minas Gerais, de 21 de setembro de 1989. URL: https://www.almg.gov. $\mathrm{br} /$ consulte/legislacao/completa/completa-nova-min.html?tipo=CON\&num=1989\&ano=1989 (проверено 29.06.2018).
} 
турами Миэ, Гумма, Токусима, Тояма и Токио [Marcovitch, Dallari 2014: 22]. В 2014 г. в штате Сан-Паулу был успешно реализован план под названием «СанПаулу в мире. План международных связей на 2011-2014 гг.»1

Ежегодно Сан-Паулу посещают много иностранных делегаций. В настоящее время правительство штата поддерживает международные связи с более чем 20 субнациональными правительствами различных государств. В общей сложности существуют около 150 проектов совместного сотрудничества в таких областях, как наука и техника, окружающая среда, общественная безопасность, образование, сельское хозяйство, права инвалидов [Marcovitch, Dallari 2014: 23-24].

Парадипломатия штата Риу-Гранди-ду-Сул. В современных условиях сфера международных связей становится решающей для развития как отдельного штата, так и всего государства. Штат Рио-Гранди-ду-Сул расположен на границе с основными бразильскими партнерами в рамках МЕРКОСУР - Аргентиной и Уругваем [Marcovitch, Dallari 2014: 48]. В этом контексте следует уточнить, что для Бразилии наиболее важными партнерами в Латино-Карибской Америке являются именно страны МЕРКОСУР - Аргентина, Уругвай, Парагвай [БРИКС - Латинская Америка... 2014: 25-26].

Парадипломатия штата Рио-Гранди-ду-Сул регулируется соответствующими положениями региональных и федеральных документов ${ }^{2}$.

Штат Рио-Гранди-ду-Сул регулярно организует поездки делегаций во главе с губернатором штата в Уругвай, Аргентину, Кубу, Португалию, Испанию, Англию, Францию, Палестину и Израиль. В настоящее время штат активно осуществляет сотрудничество с субнациональными правительствами префектуры Сига (Япония), области Венеция (Италия) и провинции Санта-Фе (Аргентина). В каждом из этих направлений осуществляются различные формы международного сотрудничества [Marcovitch, Dallari 2014: 52-53].

Подводя итог исследования парадипломатии регионов Бразилии, можно сделать следующие выводы.

Во-первых, в сфере разграничения компетенций между федеральным центром и субъектами Бразилии можно условно выделить три уровня: 1) компетенцию Союза по важнейшим политическим вопросам, а также сферу исключительной компетенции Союза; 2) совместную и конкурирующую компетенцию Союза и субъектов федерации; 3) исключительную компетенцию субъектов федерации.

Во-вторых, рассмотрев опыт парадипломатии четырех бразильских штатов (Рио-де-Жанейро, Минас-Жерайс, Сан-Паулу и Риу-Гранди-ду-Сул), следует отметить, что общей тенденцией развития международных связей данных штатов является создание, функционирование и совершенствование соответствующих специальных институциональных структур штатов, осуществляющих парадипломатию. Отличительной особенностью парадипломатии штатов Бразилии является разнообразие форм практического осуществления международных связей.

В-третьих, рассматривая наиболее успешный опыт бразильских штатов в сфере парадипломатии, можно выявить некоторые особенности и специфику каждого из рассмотренных штатов. В штате Рио-де-Жанейро наиболее детально разработаны соответствующие программы реализации международных связей регионов, проведены наиболее масштабные мероприятия международного уровня. Штат Минас-Жерайс интересен разнообразными формами осущест-

\footnotetext{
1 Decreto no 57.932, de 2 de abril de 2012. Institui o Plano de Relações Internacionais $2011-2014$ do Governo do Estado de São Paulo, e dá providências correlatas. URL: https://www.al.sp.gov.br/repositorio/ legislacao/decreto/2012/decreto-57932-02.04.2012.html (проверено 29.06.2018).

2 Constituição do Estado do Rio Grande do Sul, de 3 de outubro de 1989. URL: http://www2.al.rs.gov.br/ dal/LinkClick.aspx?fileticket=9p-X_3esaNg\%3d\&tabid=3683\&mid=5358 (проверено 29.06.2018).
} 
вления международного сотрудничества в научно-технической и инвестиционной сферах, в здравоохранении и культуре с регионами различных государств. Для парадипломатии штата Сан-Паулу характерны многочисленные встречи с иностранными делегациями и осуществление совместных проектов с иностранными партнерами. Штат Риу-Гранди-ду-Сул в связи со своим приграничным положением активно развивает приграничное сотрудничество с регионами Уругвая и Аргентины, а также уделяет внимание визитам и поездкам в регионы других государств и развитию субнациональных связей с их правительствами.

Таким образом, парадипломатия регионов Бразилии поступательно развивается в направлении дальнейшего укрепления сотрудничества с регионами соседних стран Латино-Карибской Америки, а также расширения международных связей с регионами крупнейших государств мира. На основе современного механизма разграничения полномочий и предметов ведения между центром и регионами наиболее успешный опыт международных связей в настоящее время осуществляют четыре штата Бразилии: Рио-де-Жанейро, Минас-Жерайс, СанПаулу и Риу-Гранди-ду-Сул.

\section{Список литературы}

Акимов Ю.Г. 2016. Парадипломатия как средство выражения региональной идентичности субъектов федераций. - Управленческое консультирование. № 2. C. 25-33.

БРИКС - Латинская Америка: позиционирование и взаимодействие (отв. ред. В.М. Давыдов). 2014. М.: Изд-во ИЛА РАН. 186 с.

Возможности и пределы инновационного развития Латинской Америки (отв. ред. Л.Н. Симонова). 2017. М.: Изд-во ИЛА РАН. 552 с.

Кремянская Е.А. 2015. Теория и практика федерализма: сравнительно-правовое исследование: монография. М.: Изд-во МГИМО(У). 146 с.

Кузнецов А.С. 2006. Парадипломатия: трактовки и теоретические модели. Дискурс-Пи. № 6. С. 76-78.

Плотникова О.В., Дубровина О.Ю. 2016. Межжународные связи регионов государств: характеристика и особенности. М.: Норма; ИНФРА-М. 192 с.

Яковлева Н.В., Левкин И.М. 2014. Особенности трансграничного регионального сотрудничества в форме парадипломатии. - Управленческое консультирование. № 4. С. 14-22.

Marcovitch J., Dallari P. 2014. Relações Internacionais de Ambito Subnacional: A Experiência de Estados e Municípios no Brasil. São Paulo: Instituto de Relações Internacionais-Universidade de São Paulo. 128 p.

Wolff S. 2007. Paradiplomacy: Scope, Opportunities and Challenges. - The Bologna Center Journal of International Affairs. Vol. 10. № 1. P. 141-150.

LIVANOVA Irina Vladimirovna, Cand.Sci. (Pol.Sci.), Associate Professor of Siberian Institute of International Relations and Regional Studies (14 Narodnaya St, Novosibirsk, Russia, 630075; iv-livanova17@mail.ru)

SALAMOV Ruslan Rustemovich, postgraduate student at Siberian Institute of International Relations and Regional Studies (14 Narodnaya St, Novosibirsk, Russia, 630075; ruslan5215@mail.ru)

\section{PARADIPLOMACY OF THE REGIONS OF BRAZIL: AUTHORITIES AND AREAS OF RESPONSIBILITY}

Abstract. The main purpose of this article is the analysis of the main aspects in the sphere of paradiplomacy of the regions of Brazil. The authors identify several levels in the sphere of division of powers and jurisdictions of the regions of Brazil and 
the federal center. The first level is the competence of the Union and the sphere of the exclusive competence of the Union. The second level is represented by joint and competing competence of the Union and federal entities (the states, the Federal District and municipalities). Exclusive competence of the federal entities can be conditionally included to the third level (and this competence is residual). The authors also give an analysis of paradiplomacy of the four leading Brazilian states; they are Rio de Janeiro, Minas Gerais, São Paulo and Rio Grande do Sul. An important factor in the development of interregional connections of these states is the creation of the special institutional structure. In addition, paradiplomacy of all the abovementioned states is developed in accordance with the provisions of federal and regional documents.

Keywords: paradiplomacy, authorities, areas of responsibility, Union, Federal District, states

НАГУСЛАЕВА Елизавета Альбертовна - магистрант Института стран Азии и Африки Московского государственного университета им. М.В. Ломоносова (125009, Россия, г. Москва, ул. Моховая, 11, cmp. 1; nageliz@icloud.com)

\section{РЕЛИГИОЗНАЯ ПОЛИТИКА СИ ЦЗИНЬПИНА}

Аннотация. Статья посвящена изучению религиозной политики Коммунистической партии Китая в период правления Си Цзиньпина с 2013 г. по настоящее время. Приводятся изменения в курсе вероисповедальной политики при действующей власти, даются его специфические характеристики. Автор описывает практическое применение государственных установок по отношению к религии на примере отдельных конфессий и делает вывод о противоречивости осуществляемой властью религиозной политики.

Ключевые слова: религиозная политика, КПК, Китай, Си Цзиньпин

Д ействующим главой Китайской Народной Республики с 2013 г. является Си Цзиньпин. За время его правления во внутренне- и внешнеполитической стратегии Китая обозначились определенные изменения, многие из которых вызвали бурную реакцию мирового сообщества. Среди них масштабная антикоррупционная кампания, централизация власти, обострение территориальных споров в Восточно-Китайском и Южно-Китайском морях, а также принятие ряда законов, идеологически основанных на Документе № 9 2013 г. - циркуляре КПК, отразившем негативное отношение власти к «западным ценностям» (консультационная демократия, «универсальные» ценности, неолиберализм, свобода прессы и т.д.), связанное со стремлением партии усилить контроль над каждым аспектом социальной жизни, способным представлять угрозу режиму [Fu 2015]. Во внутренней политике стремление партии к централизации власти обусловливает тенденцию к ужесточению религиозной политики, росту степени контроля в религиозной сфере жизни общества.

При действующей администрации концептуально новым в риторике партии стал акцент на возросшую роль сети Интернет как канала распространения экстремистской и террористической угроз, который на практике выливается в ведение тщательного контроля за китайским сегментом глобальной сети. В 2016 г. состоялась публикация новых Правил регулирования религиозной деятельности ${ }^{1}$. Новые положения отражают основные идеи политического курса администрации Си Цзиньпина: противостояние иностранному влиянию, необходимость контроля над информационными потоками в глобальной сети, борьба с угрозами терроризма, экстремизма и сепаратизма [杨凯乐 2016].

\footnotetext{
${ }^{1}$ State Council highlights key tasks in 2016 legislative work. - The State Council of the People's Republic of China. URL: http://english.gov.cn/policies/latest_releases/2016/04/13/content_281475326751655.htm (accessed 15.11.2018).
} 